\title{
EDUCAR ATRAVÉS DA(S) MEMÓRIA(S) ${ }^{1}$
}

\section{EDUCATING THROUGH MEMORY(IES)}

\author{
ARAÚJO, Helena Maria Marques ${ }^{2}$
}

\section{RESUMO}

Esse texto pretende conceituar e problematizar memória vista como um instrumento de empoderamento identitário através de processos educativos outros, quer sejam na escola, ou em espaços educativos não formais, ou até mesmo espaços educativos informais. Analiso especificamente como os "lugares de memória" educam, ou seja, são espaços educativos não formais. Para isso, pretendo diferenciar os conceitos de educação formal, não formal e informal relacionando-os aos possíveis fortalecimentos de identidades locais de diferentes grupos sociais através da construção $\mathrm{da(s)}$ memória(s) e da ressignificação das histórias locais, principalmente através dos chamados "lugares de memória". Os museus são guardiões e divulgadores de culturas e ideologias de grupos sociais específicos. Sendo assim, me concentro na compreensão e correlações da missão educativa dos museus e dos "lugares de memória" em geral.

Palavras-Chave: Lugares de memória; Espaços educativos não formais; Memórias contra hegemônicas; Memória; Espaços educativos formais.

\section{ABSTRACT}

This article intends to conceptualize and problematize memory as an instrument of identity empowerment by means of other educational processes, whether at school, in non-formal educational spaces or even informal educational spaces. I analyze specifically how "places of memory" educate, that is, how they are non-formal educational spaces. I intend to differentiate the concepts of formal, non-formal and informal education by relating them to the possible strengthening of local identities of different social groups through the construction of memor(ies) and the re-signification of local histories, mainly through the socalled "places of memory". Museums are guardians and disseminators of cultures and ideologies of specific social groups. Therefore, I focus on the understanding and correlations of the educational mission of museums and "places of memory" in general.

KeYWORDS: Places of memory; Non-formal educational spaces; Counter-hegemonic memories; Memory; Formal educational spaces.

\footnotetext{
${ }^{1}$ A autora Helena Maria Marques Araújo agradece à Coordenação de Aperfeiçoamento de Pessoal de Nível Superior (CAPES) e à UNIRIO (Universidade Federal do Estado do Rio de Janeiro), pela bolsa de estudo para pós-doutoramento.

2 Professora do Programa de Pós-Graduação em Ensino de Educação Básica - PPGEB/CAp-UERJ; PósDoutoranda da Universidade Federal do Estado do Rio de Janeiro - UNIRIO. e-mail: hmaraujo@ig.com.br
} 


\section{INTRODUÇÃO}

Esse texto pretende conceituar e problematizar a memória como um instrumento de empoderamento identitário através de processos educativos outros, quer sejam na escola, ou em espaços educativos não formais, ou até mesmo informais.

Segundo Tomaz Tadeu da Silva (1999) toda a cultura é pedagógica, ou seja, ensina alguma coisa e toda a cultura é fruto de um momento histórico, de um determinado contexto. Nesse texto analiso como os "lugares de memória" educam, ou seja, são por excelência espaços de educação não formal. Para isso, pretendo diferenciar os conceitos de educação formal, não formal e informal relacionando-os aos possíveis fortalecimentos de identidades locais de diferentes grupos sociais através da construção da(s) memória(s) e da ressignificação das histórias locais, principalmente através dos chamados "lugares de memória"133 (NORA, 1993).

Para Nora (id) os "lugares de memória" são onde depositamos nossa memória coletiva, onde trançamos memórias individuais e coletivas, memórias de camadas populares ou de elites. Podem ser materiais ou não materiais, como por exemplo: o sabor da comida, os ritmos musicais, os valores religiosos, dentre outros. Os "lugares de memória", por definição, são permeados de relações de poder (CHAGAS, 2005, 2007, 2008). Logo, os "lugares de memória" relacionados às camadas dominantes têm obras e práticas culturais materiais e imateriais mais valorizadas do que aquelas das camadas populares.

Nesse texto interessa-nos os museus, que são guardiões e divulgadores de culturas e ideologias de grupos sociais específicos. Sendo assim, nos concentramos na compreensão e correlações da missão educativa dos museus (APPADURAI e BRECKENRIDGE, 2007) e dos "lugares de memória" em geral.

\section{O ESPAÇO NÃO FORMAL DE EDUCAÇÃo}

A educação é uma prática social complexa e constante, multifacetada. Ocorre também fora na escola, em outras instâncias culturais, como: bibliotecas, museus, cinemas, televisão, internet, família, clube, bairro, vizinhança etc.

A educação formal tem sua centralidade na escola, tendo em vista ser esta o espaço por excelência do saber sistematizado, porém não é só a escola um espaço de aprendizagem. Existem outros espaços e lugares que também educam, são os chamados espaços educativos não formais.

Nessa pesquisa fomos envolvidos por questões e indagações específicas relacionadas à educação, são elas: a conceituação e diferenciação entre os espaços educativos formais, não formais e informais; e de que forma as práticas sociais e/ ou

\footnotetext{
${ }^{3}$ A expressão "lugares de memória" foi cunhada por Pierre Nora em sua obra intitulada Entre memória e história: a problemática dos lugares em 1993.
} 
educacionais desses "lugares de memória" podem fortalecer identidades sociais e culturais através do empoderamento identitário.

O conhecimento é um conjunto de saberes socialmente referenciado e legitimado imersos num caldo cultural. Portanto, a escola não é o único "lugar de conhecimento" e de transformação de subjetividades (SILVA, 1999), é o lugar de construção desses saberes da educação formal e de certificação dos indivíduos.

Além da educação formal e não formal, também existe a educação informal. Segundo Cazelli e Vergara (2007), a intencionalidade da instituição é o principal traço que diferencia a educação não formal da informal, como podemos perceber no trecho abaixo:

Reunindo essas características acima apresentadas, falta assinalar uma que é o destaque da educação não formal e que a diferencia, por exemplo, da informal. Esta característica é a intencionalidade de instituição, bem como a dos idealizadores das ações (no caso dos museus, os conceptores das exposições e das atividades de cunho educacional/ cultural), com objetivos de unir cultura, saberes e lazer (CAZELLI \& VERGARA, 2007, p.7).

Desses três tipos de espaços educativos, em nossa pesquisa interessa-nos primordialmente o estudo dos espaços educativos não formais. Os "lugares de memória", quer sejam museus, arquivos dentre outros, possuem cultura própria, especificidades. Nesse caso nos debruçamos sob a dimensão educativa dos museus como "lugares de memória" e de empoderamento identitário.

\section{CONTEXTUALIZANDO A EDUCAÇÃO NÃO FORMAL}

Com os teóricos Jaume Trilla \& Elie Ganem (2008) e Maria da Glória Gohn (2010) mapearemos a educação não formal desde seu surgimento.

A educação não escolar ou não formal sempre existiu desde os primórdios da humanidade. Só a partir do século XIX a escola foi alçada à exemplaridade da ação educativa. O objetivo das políticas educacionais dos séculos XIX e XX foi primordialmente o acesso de todos à escola o maior tempo possível. Nessa época, segundo Trilla (2008) elabora-se uma dimensão pedagógica em torno da escola, já que a educação, particularmente a escola, passa a ser entendida como essencial a toda a sociedade.

Porém, segundo Trilla (2008) a estrutura educacional impõe limites porque a escola não está apta para todo tipo de objetivo educacional. Logo, se faz necessário criar outros espaços e meios educacionais complementares à escola e que passa a ser denominada de "não formal". 
A educação não formal ganha força a partir da $2^{a}$ metade do século $X X$, principalmente a partir dos anos 60 e 70 , sendo que esse contexto se originou devido a fatores sociais, econômicos, políticos etc, como por exemplo, a demanda por educação de setores tradicionalmente excluídos, quer sejam: adultos, minorias étnicas, idosos etc.). 0 contexto da Guerra Fria, os movimentos da Contracultura, o Movimento Negro e outros movimentos impulsionam diferentes grupos na luta por seus direitos políticos e sociais.

A educação não formal brasileira está intrinsecamente relacionada ao surgimento da pedagogia libertadora de Paulo Freire nos anos 50 e 60, voltada para a educação de adultos trabalhadores (TRILLA, 2008).

Paralelo a isso, trabalhos como os de P.H.Combs, ( $A$ crise mundial da educação, 1968), de Edgar Faure (Aprender a ser, 1972), e de Jacques Delors (Educação - Um tesouro a descobrir, 1996) foram baluartes fundamentais para a compreensão do processo educacional não formal.

A educação não formal se caracteriza pela metodologia, ou o procedimento, ou o agente que gera o processo educacional, segundo Trilla (2008). Para este autor, a educação formal compreenderia o "sistema educacional" institucionalizado, fatiado no tempo"; já a educação não formal seria toda atividade organizada, sistemática, educativa, realizada fora do marco do sistema oficial que facilite aprendizagens; e a educação informal, um processo assistemático em que as pessoas adquirem e acumulam conhecimentos, habilidades, atitudes na interação com o meio durante toda a vida.

Na educação informal dialogamos com o que Nilda Alves (1999) denomina redes educativas do cotidiano ${ }^{4}$, ou seja, são práticas, valores e saberes transmitidos num determinado universo cultural.

Segundo o critério metodológico, Trilla (2008) afirma que a educação não formal se distancia dos procedimentos escolares clássicos. Estruturalmente, a educação formal e a não formal se diferenciam por sua inclusão ou exclusão do sistema educativo regular e sistematizado. A Educação não formal, por situar-se fora do sistema de ensino regrado, permite o uso de determinadas metodologias. Para esse autor a educação não formal é: "Conjunto de processos, meios e instituições diferenciadamente concebidos em função de objetivos explícitos de formação ou instrução não diretamente voltados à outorga dos graus próprios do sistema educacional regrado" (TRILLA, 2008, p. 42).

Para Trilla (2008), a educação não formal engloba diversas dimensões como: no trabalho (programas de reciclagem profissional, escolas-oficinas etc); no lazer e na cultura (animação sociocultural, pedagogia do tempo livre etc); na educação social (educadores de rua, programas para penitenciários etc); na própria escola (atividades extracurriculares, visitação a museus, a outras instituições culturais etc).

\footnotetext{
${ }^{4}$ Rede educativa do cotidiano é uma expressão cunhada por Nilda Alves em diversos de seus escritos, como "O Sentido da Escola" (1999).
} 


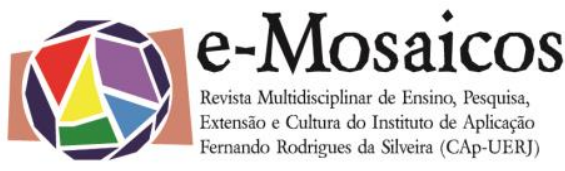

DOI: $10.12957 /$ e-mosaicos.2017.30260

Ghanem (2008) afirma que a educação formal decorre de um conjunto de mecanismos de certificação, além de referendar seu caráter sistemático e esquemático. O campo da educação formal é contrário ao da educação não formal. Além disso, caracteriza a educação não formal, ao contrário da educação formal, os conteúdos selecionados e adaptados levando em consideração as necessidades imediatas das suas áreas de atuação, sendo mais contextualizados, funcionais, de caráter menos abstrato. Também sublinha a não obrigatoriedade da educação não formal de acoplar-se a estruturas, hábitos e formas organizativas próprias da escola (calendários, horários e aspectos operacionais).

A educação formal, não formal e informal se intercruzam, por exemplo: na escola, os alunos recebem a educação formal sistematizada, com a possibilidade da inclusão de atividades extracurriculares (educação não formal), além dos processos educacionais informais que resultam das interações não planejadas entre os próprios alunos (educação informal).

A educação não formal pode ser uma opção de superação de carências da educação formal para as classes menos favorecidas (GHANEM, 2008). Sob esse ângulo nos baseamos em Trilla (2008) quando afirma que não podemos perder a crítica sobre a educação não formal, tendo em vista que ela pode ser tão maléfica, elitista ou classista quanto a educação formal (id, p.54) porque também pode ser tão alienante, burocrática, ineficiente, cara, obsoleta, estática, manipuladora, estereotipada e uniformizadora quanto a formal.

A educação não formal não vai dar solução aos problemas da educação formal, porém ela pode facilitar o acesso mais amplo e justo a uma educação de maior qualidade possível. "(...) certamente há propostas educacionais não formais que, comparadas com as formais, são de "segunda categoria", mas há também outras nas quais essa hierarquia qualitativa se inverte de modo contundente." (id, p. 160).

Gohn (2010) entende que o aprendizado gerado e compartilhado na educação não formal não é espontâneo, há intencionalidades e propostas. Tem diversos pontos de encontro teóricos com Trilla (2008), porém em outros se distancia dele.

A concepção de Gohn (2010) sobre educação não formal se articula à educação cidadã, pois ela entende que seu eixo deve ser formar para a cidadania e emancipação social dos indivíduos. Também esclarece que a educação está muito articulada à ideia de cultura, tem um campo próprio, intencionalidades e vem se consolidando desde as últimas décadas do século XX. Paradoxalmente, para a mídia e o senso comum não é considerada educação porque não está constituída por processos escolarizados.

Gohn (2010) não discorda de Trilla (2008) quanto à intencionalidade, mas apresenta uma visão singular quando frisa que o eixo da educação não formal é formar para a cidadania e emancipação social dos indivíduos. "A intencionalidade não é o único marco diferencial entre a formal e a não formal, porque existe nas duas, 
mas é ela que demarca um objetivo específico na educação não formal - formar para a cidadania." (id, p. 34)

Afirma que a educação que recebemos dos pais é a educação informal, já a que recebemos na escola denomina-se educação formal e a educação do mundo, aquela advinda da experiência, dos espaços e ações coletivos cotidianos chama-se educação não formal.

As áreas, que segundo Gohn (2010), demandam a educação não formal são as áreas de formação para a cidadania e a de trabalhos voltados para a emancipação social de indivíduos, grupos e coletivos sociais. A educação para a cidadania incorpora a educação para a justiça social; os direitos humanos, sociais, políticos e culturais; a liberdade; a igualdade e diversidade cultural; a democracia; a favor do fim dos preconceitos e qualquer forma de discriminação; o exercício da cultura e manifestações das diferenças culturais (Gohn, 2010).

Sendo assim, Gohn (2010) articula sua concepção de educação não formal ao campo da educação cidadã, como fica registrado no trecho abaixo:

(...) Na educação não formal, essa educação volta-se para a formação de cidadãos (as) livres, emancipados, portadores de um leque diversificado de direitos, assim como de deveres para com o (os) outro(s).

Chegamos portanto ao conceito que adotamos para educação não formal. É um processo sociopolítico, cultural e pedagógico de formação para a cidadania, entendendo o político como a formação do indivíduo para interagir com o outro em sociedade. Ela designa um conjunto de práticas socioculturais de aprendizagem e produção de saberes, que envolve organizações/ instituições, atividades, meios e formas variadas, assim como uma multiplicidade de programas e projetos sociais (GOHN, 2010, p. 33).

Segundo Gohn (2010) na educação formal - nas escolas- é o educador que é fundamentalmente o professor, enquanto que na educação não formal existe o educador social. Mas, nesta o grande educador é o "outro", aquele com quem interagimos ou nos integramos. Na educação informal são os pais, a família, em geral os amigos, os vizinhos, os colegas de escola, a igreja paroquial, os meios de comunicação de massa etc.

(...) A não formal ocorre em ambientes e situações interativas construídos coletivamente segundo diretrizes de dados grupos, usualmente a participação dos indivíduos é optativa, mas ela também poderá ocorrer por forças de certas circunstâncias da vivência histórica de cada um, em seu processo de experiência e socialização, 


\begin{abstract}
pertencimentos adquiridos pelo ato da escolha em dados processos ou ações coletivas. Há na educação não formal uma intencionalidade na ação, no ato de participar, de aprender e de transmitir ou trocar saberes. A informal opera em ambientes espontâneos, onde as relações sociais se desenvolvem segundo gostos, preferências ou pertencimentos herdados (GOHN, 2010, p. 18).
\end{abstract}

É a partir dos anos 2000, segundo Gohn, que a educação não formal se difunde e se dá o reconhecimento e a popularização de outras concepções de formas e meios educacionais feitos fora da escola, mas com objetivos educacionais. $\mathrm{Na}$ França, Alemanha e Espanha temos publicações com a denominação de educação social, no campo da pedagogia social segundo Gohn (2010), que configuram a educação não formal.

Para Gohn (2010) a educação não formal é definida pelo que não é, mas é importante que passemos a conceitua-la e defini-la pelo que é. Normalmente contrapõe-se educação formal a não formal, mas a autora não concorda e acha que elas se complementam. Porém, não é complementar no sentido de fazer o que a escola não faz, mas sim, na ideia de desenvolver campos de aprendizagem específicos.

A educação não formal não possui uma dimensão normatizadora e nem emite certificações, trabalha com uma outra lógica de espaço e tempo. Não tem currículo definido a priori, tanto no que diz respeito aos conteúdos, temas ou habilidades.

Ainda acrescenta Gohn (2010) que a educação não formal é diferente da educação informal, que é herdada e naturalizada, enquanto a primeira é adquirida de modo intencional e empodera os seres humanos a se tornarem cidadãos do mundo. Os objetivos são cunhados durante a interação vivenciada, incentivando e criando-se um processo educativo. Um objetivo na educação não formal é a transmissão da informação de forma não escolarizada e a formação política e sociocultural dos indivíduos.

Gohn (2010) identifica as características de cada tipo de educação diferenciando a educação informal da não formal, ou seja:

- educação informal: conhecimento não sistematizado, atuação no campo das emoções e sentimentos, é um processo permanente e não organizado;

- educação não formal: não organizada por séries, idades, conteúdos; atua sobre aspectos subjetivos do grupo; trabalha e forma a cultura política de um grupo; cria laços de pertencimento; empodera a construção identitária coletiva do grupo; influencia na formação do capital social de um grupo, que Gohn prefere chamar de acervo sociocultural e político; é fundamentada, segundo ela, em vários critérios de solidariedade e identificação de interesses comuns, parte da cidadania coletiva e pública do grupo. 
O processo político-pedagógico de aprendizagem e produção de saberes dos espaços educativos não formais possui várias dimensões para Gohn, dentre elas: aprendizagem política dos direitos dos indivíduos como cidadãos, ou aprendizagem para a cidadania; aprendizagem dos indivíduos para atuarem no trabalho; aprendizagem pela cultura, de conteúdos que possibilitem aos indivíduos fazer uma leitura do mundo do ponto de vista de compreensão do que se passa ao seu redor, gerada pelo acesso a recursos culturais como museus, bibliotecas, shows, palestras etc. Esses são aprendizados que se desdobram em autoaprendizagem e aprendizagem coletiva adquiridas a partir da experiência em ações coletivas, organizadas por eixos temáticos (questões étnico-raciais, gênero, geracionais e de idade etc) com apoio de organizações institucionalizadas ou não.

As práticas da educação não formal se desenvolvem usualmente extramuros escolares, nas organizações sociais, nos movimentos sociais, nas associações comunitárias, nos programas de formação sobre direitos humanos, cidadania, práticas identitárias, lutas contra desigualdades e exclusões sociais (GOHN, 2010, p. 36).

Os resultados da educação não formal são, segundo Gohn (2010): consciência de ação mais coletiva; construção e reconstrução da concepção de mundo; contribuição para um empoderamento identitário.

Sendo assim, veremos em seguida como esses espaços educativos não formais também perpassam os territórios da memória.

\section{OS "LUGARES DE MEMÓRIA" EDUCAM}

O conceito "lugares de memória" foi cunhado por Pierre Nora (1993) e engloba socialmente os museus, escolas, universidades, sindicatos, fundações culturais, ruínas, conjuntos arquitetônicos, agremiações, clubes, arquivos, centros de documentação, dentre outros. São criados pelas diferentes sociedades através do tempo para manter a história a ser contada (NORA, 1993).

Para Nora (1993) os "lugares de memória" ancoram nossa memória coletiva. É neles que se cruzam memórias individuais e coletivas, se materializam memórias de camadas populares ou elites. Eles podem ser materiais ou não materiais, como 0 sabor da comida, os ritmos musicais, os valores religiosos etc.

Nos "lugares de memória", por definição, se entrelaçam relações de poder (CHAGAS, 2000, 2002). Logo, os "lugares de memória" relacionados às camadas dominantes tem obras e práticas culturais materiais e imateriais mais valorizadas do que aquelas das camadas populares.

Pierre Nora no artigo denominado Entre memória e história. A problemática dos lugares (1993) escreve sobre o tempo presente, em que a aceleração vai 
gerando uma sensação de perda do passado e de um eterno presente. Logo, surge a angustiosa necessidade humana de guardar, segurar os vestígios do passado, os seus "restos", devido ao efeito bombástico de tal aceleração contemporânea.

Nora (1993) também afirma sobre diferenciação entre história e memória, como podemos, observar no trecho abaixo:

A história é a reconstrução sempre problemática e incompleta do que não existe mais. A memória é um fenômeno sempre atual, um elo vivido no eterno presente, a história, uma representação do passado. Porque é afetiva e mágica, a memória não se acomoda a detalhes que a confortam, ela se alimenta de lembranças vagas, telescópicas, cenas, censura ou projeções. A história, porque operação intelectual e laicizante, demanda análise e discurso crítico. A memória instala a lembrança no sagrado, a história a liberta e a torna sempre prosaica. (id, p.9)

O conceito de "lugares de memória" tem um duplo pertencimento, são lugares híbridos, mistos e mutantes devido, dentre outros, à mediação entre o mundo dos mortos e o mundo dos vivos, entre a memória verdadeira e a memória alcançada pela história (Nora, id).

Para finalizar, os "lugares de memória" nos permitem reconstruir o passado, relembrá-lo, logo lembrar ou esquecer o que grupos sociais desejam e querem ensinar. Por excelência os "lugares de memória" são espaços educativos não formais que possibilitam "guardar" o passado (id), ressignificar a história, construir a memória e fortalecer valores, práticas sociais e culturais - identidades culturais. Não é isso o que os museus hegemônicos ou contra hegemônicos fazem: construir memórias e empoderar identidades?

Vários estudiosos e museólogos lutam - como Marandino $(2000,2005)$ - pela formulação cada vez mais necessária de uma pedagogia museal, Essa autora tem consciência da especificidade metodológica e estratégica necessária a uma pedagogia museal. Uma pedagogia museal permitirá uma maior eficácia na construção e transmissão da(s) diferentes memória(s) e história.

Por fim, constatamos o quanto as redes educativas do cotidiano emergem nas práticas cotidianas do universo cultural dos museus, a despeito de muitas vezes elas nos parecerem invisíveis, mas presentes de forma sutil e firme.

As imagens, os quadros, as esculturas, mobiliário, dentre outros, são como palavras geradoras, freireanamente interpretando, que acionam a memória coletiva. Se educar é metamorfosear subjetividades e produzir novas identidades (SILVA, 1999), não é isso o que os "lugares de memória" despertam e incentivam, como os museus? 
Porém, uma das questões primordiais nos museus é que a memória ali construída pode estar a serviço do passado ou do presente, pode servir à emancipação dos indivíduos, ou à sua submissão. Sendo assim, entendemos que esta é uma reflexão e problemática que permeia todo nosso estudo sobre relações entre memória, educação e museus.

\section{REFERÊNCIAS BIBLIOGRÁFICAS}

ABREU, Regina e CHAGAS, Mário (orgs.). Memória e patrimônio: ensaios contemporâneos. Rio de Janeiro: DP\&A, 2003.

ALVES, Nilda.O sentido da escola. Rio de Janeiro: DP\&A, 1999.

AMADOR, Janaína \& FERREIRA, Marieta de Moraes (orgs.) Memória e tradição. In: Usos e abusos da História Oral. Rio de Janeiro: Editora FGV. 2002.

APPADURAI, Arjun \& BRECKENRIDGE, Carol A. (Trad. STORINO, Claudia M. P. ). Museus são bons para pensar: o patrimônio em cena na Índia. In: MUSAS - Revista Brasileira de Museus e Museologia, n.3, 2007. Rio de Janeiro: Instituto do Patrimônio Histórico e Artístico Nacional, Departamento de Museus e Centros Culturais, 2004.

ARAÚJO, Helena Maria Marques. Memória e produção de saberes em espaços educativos não formais. In: Cadernos do CEOM - Educação Patrimonial, Chapecó: 2007.

. Museu da Maré: entre educação, memórias e identidades. Tese (Doutorado em Educação). Rio de Janeiro: PUC-Rio, 2012.

BOSI, Ecléa. Memória e Sociedade: lembranças de velhos. São Paulo: T.A. Queiróz, 1979.

CANDAU, Vera Maria (org.). Sociedade, educação e cultura(s): questões e propostas. Petrópolis, RJ: Vozes, 2002.

CASTELLS, Manuel. O poder da identidade. São Paulo: Paz e Terra, 1999.

CAZELLI, Sibele, VERGARA, Moema. O passado e o presente das práticas de educação não formal na cidade do Rio de Janeiro. In: I Encontro de História da Educação do estado do Rio de Janeiro._Niterói, RJ;. CD-ROM do IEHEd - RJ, 2007.

CHAGAS, Mário de Souza. Museu, Memórias e Movimentos Sociais. In: Museus Agentes de Mudança Social e Desenvolvimento. Revista Museu. 2008. ISSN 19816332 
. Museu, museologia e pensamento social brasileiro. In: Cadernos CEOM. Chapecó: Argos, 2005.

\& STORINO, Cláudia M. P. Os museus são bons para pensar, sentir e agir. In: MUSAS - Revista Brasileira de Museus e Museologia, n.3, 2007. Rio de Janeiro: Instituto do Patrimônio Histórico e Artístico Nacional, Departamento de Museus e Centros Culturais, 2004.

COMBS, P.H. A crise mundial da educação. Paris: PUFF, 1968.

DELORS, Jacques. Relatório para a UNESCO Educação - Um tesouro a descobrir. 1996.

FAURE, Edgar. Relatório para a UNESCO Aprender a Ser. 1972.

GOHN, Maria da Glória Marcondes. Educação não formal e o educador social: atuação no desenvolvimento de projetos sociais. São Paulo: Cortez, 2010. . Movimentos sociais e educação. São Paulo: Cortez, 2009.

HALBWACHS, Maurice. Memoria coletiva. São Paulo: Vértice, 1990.

HALL, Stuart. A identidade cultural na pós-modernidade. Tradução Tomaz Tadeu da Silva, Guaracira Lopes Louro. Rio de Janeiro: DP\&A, 2001.

KERSTEN, Márcia Scholz de Andrade \& BONIN, Anamaria Aimoré. Para pensar os museus, ou "Quem deve controlar a representação do significado dos outros?". In: MUSAS - Revista Brasileira de Museus e Museologia, n.3, 2007. Rio de Janeiro: Instituto do Patrimônio Histórico e Artístico Nacional, Departamento de Museus e Centros Culturais, 2004.

LE GOFF, Jacques. História e Memória. Campinas; Editora da Unicamp, 1990.

MARANDINO, Martha. A pesquisa educacional e a produção de saberes nos museus de ciência. In: História, Ciências, Saúde - Manguinhos.vol. 12 suppl.0 Rio de Janeiro: 2005. Print ISSN 0104-5970.

. Museu e escola: parceiros na educação científica do cidadão. In: CANDAU, Vera Maria (org.). Reinventar a escola. Petrópolis, RJ: Vozes, 2000.

MESQUITA, Cláudia. Algumas reflexões sobre o potencial pedagógico dos museus da cidade do Rio de Janeiro para a construção do conhecimento em história nos ensinos fundamental e médio. In: Site da Anpuh - XII Encontro Regional de História, Anais, 2006.

MOREIRA, Antonio e CANDAU, Vera (orgs.). Multiculturalismo: diferenças culturais e práticas pedagógicas. Petrópolis, RJ: Vozes, 2008. 
NORA, Pierre. Entre memória e história: a problemática dos lugares. São Paulo: Projeto História, n. 10, dez. 1993.

POLLACK, Michel. Memória e identidade social. In: Estudos Históricos. No 10, Rio de Janeiro: Editora FGV, 1992.

Memória, esquecimento e silêncio. Estudos Históricos. Rio de Janeiro: Ed. CPDOC/ FGV, v. 2, n.3, 1989.

RICOEUR, Paul. A memória, a história, o esquecimento. Campinas, SP: Editora da UNICAMP, 2007.

SARLO, Beatriz. Tempo passado: cultura da memória e guinada subjetiva. São Paulo: Companhia das Letras; Belo Horizonte: UFMG, 2007.

SILVA, Tomaz Tadeu da. Documentos de identidade: uma introdução às teorias do currículo. Belo Horizonte: Autêntica, 1999.

TRILLA, Jaume \& GANEM, Elie. ARANTES, Valéria Amorim. Educação formal e não formal: pontos e contrapontos. São Paulo: Summus, 2008. 